\title{
A violência na escola: abordagens teóricas e propostas de prevenção
}

\section{School violence: theoretical approaches and proposals of prevention}

\author{
Joyce Mary Adam de Paula e Silva ${ }^{1}$ \\ Leila Maria Ferreira Salles ${ }^{2}$
}

\begin{abstract}
RESUMO
O objetivo deste texto é proceder a uma reflexão, por meio de uma revisão de estudos na área, sobre as tendências teóricas que têm permeado a discussão sobre violência escolar. Busca-se caracterizar propostas de intervenção na escola, implementadas por iniciativa governamental, para prevenir violência e que têm como proposta central o incentivo às relações democráticas na escola. Aponta-se neste estudo que o incentivo às relações democráticas, embora importante, é insuficiente para trabalhar a violência no âmbito escolar. Os determinantes da violência extrapolam as características individuais e grupais dos indivíduos envolvidos e não se restringem às vivências do contexto escolar. Assim, é importante que os programas de prevenção à violência ampliem a reflexão sobre os diferentes aspectos presentes na violência escolar.
\end{abstract}

Palavras-chave: escola; violência; propostas de intervenção.

\begin{abstract}
The objective of this text is maturing a reflection, by means of a revision of studies in the area, on the theoretical trends involved on current discussions on school violence. We try to characterize proposals of intervention in the school environment implemented for governmental initiative to prevent violence. These proposals have, as a core objective, the incentive of democratic relations at school. It is pointed in this study that this important incentive to install democratic relations is insufficient to prevent violence pertaining the school scope. The violence determinants go beyond the individual and
\end{abstract}

1 Professora livre docente do Departamento de Educação do Instituto de Biociências da Universidade Estadual Paulista de Rio Claro (UNESP), São Paulo, Brasil. Coordenadora do programa de Pós-graduação em Educação. Tem pesquisado a problemática das organizações educacionais e da violência escolar.

2 Professora Doutora, chefe do departamento de Educação do Instituto de Biociências da Universidade Estadual Paulista de Rio Claro (UNESP), São Paulo, Brasil. Tem pesquisado a questão da violência de jovens e violência escolar, com foco na análise das relações familiares. 
group characteristics of the people involved, and they are not restricted to the school context. Thus, it is important that the violence prevention programs extend the reflection on the different aspects concerned to school violence. Keywords: school; violence; proposals of intervention.

\section{Algumas considerações sobre escola e violência}

O objetivo deste texto é proceder a uma reflexão, por meio de uma revisão de alguns estudos na área, sobre as tendências teóricas que têm permeado a discussão sobre violência escolar e discutir projetos de intervenção na escola para prevenir violência que têm como proposta central o incentivo às relações democráticas na escola e que foram implementadas por iniciativa governamental.

A problemática da violência, seja aquela em que o jovem é vitima seja aquela que é protagonizada por ele, vem provocando crescente perplexidade e sendo objeto de grande preocupação no meio escolar. Em geral, violência é conceituada como um ato de brutalidade, física e/ou psíquica contra alguém e caracteriza relações interpessoais descritas como de opressão, intimidação, medo e terror. A violência não pode ser reduzida ao plano físico, podendo se manifestar também por signos, preconceitos, metáforas, desenhos, isto é, por qualquer coisa que possa ser interpretada como aviso de ameaça, o que ficou conhecido como violência simbólica. Segundo Gilberto Velho (2000), a violência não se limita ao uso da força física, mas à possibilidade ou ameaça de usá-la constitui dimensão fundamental de sua natureza, associando-a a uma ideia de poder, quando se enfatiza a possibilidade de imposição de vontade, desejo ou projeto de um ator sobre o outro.

O que especifica a violência é o desrespeito, a negação do outro, a violação dos direitos humanos que se soma à miséria, à exclusão, à corrupção, ao desemprego, à concentração de renda, ao autoritarismo e às desigualdades presentes na sociedade brasileira.

Nas escolas, segundo os professores, a violência está aumentando não somente do ponto de vista quantitativo como também do qualitativo. Os tipos de violência assinalados por eles como estando mais presentes no dia a dia escolar são as ameaças e agressões verbais entre alunos e entre estes e os adultos. Os professores em seus relatos têm destacado que a violência, principalmente o desrespeito, é uma constante no meio escolar. Eles indicam que a violência na escola pública está banalizada, provocando inclusive que vários atos deixam até de serem percebidos como violentos. Embora menos frequentes, as agressões físicas também estão presentes. 
Charlot (2002) caracteriza a violência escolar como: violência na escola, violência à escola e violência da escola. $\mathrm{O}$ autor argumenta que esta distinção é importante no sentido de que se a escola é, em grande medida, impotente com respeito à violência na escola, isto é, a violência que é reflexo do mundo externo, ela não o é com respeito a sua ação face à violência da escola e à escola.

Sposito (2001), em artigo em que faz um balanço sobre as pesquisas sobre violência escolar no Brasil, destaca que a relação conflituosa entre alunos e professores tem gerado um medo constante entre professores, que apelam para a segurança policial, o que afeta a qualidade da interação educativa e o clima escolar. O autor considera que os anos 1990 sejam um momento de mudanças no padrão da violência nas escolas públicas englobando agora não só atos de vandalismo, mas também práticas de agressões interpessoais. As agressões entre professores e alunos tornam-se cada vez mais presentes nas escolas públicas brasileiras a ponto de haver um grande número de afastamentos de docentes por problemas de saúde. Os estudos, ao indicarem a presença de manifestações de violência em outros grupos sociais, apontam também para uma crise da função socializadora da escola. Ou seja, esses atos violentos sinalizam as dificuldades da unidade escolar em criar possibilidades para que tais condutas assumam a forma de um conflito capaz de ser acertado no âmbito da convivência democrática (SPOSITO, 2001, p. 100).

O propósito deste texto é, então, fazer uma revisão sobre algumas tendências teóricas que têm permeado a discussão da violência escolar e sobre os programas de prevenção à violência.

\section{As perspectivas teóricas de análise da violência no âmbito escolar: uma revisão}

A revisão da literatura sobre o assunto evidencia algumas perspectivas teóricas, que embora não sejam únicas, têm se destacado e fundamentado as análises e as investigações empíricas sobre a violência escolar.

A revisão sobre violência escolar aponta que o significado de violência e de comportamentos violentos é distinto nos diferentes estudos. Em alguns trabalhos apenas os atos de violência física são estudados. Outros, no entanto, enfocam a violência verbal, as agressões e, inclusive, as autoagressões (suicídios), enquanto que outros ainda atentam para o comportamento de oposição às atividades escolares, a depredação da escola, os furtos e os comportamentos delinquentes. 
Um conjunto de estudos sobre violência escolar tem procurado quantificar a incidência da violência nas unidades escolares. No levantamento que fez sobre as pesquisas em violência escolar Sposito (2001) assinala que os primeiros trabalhos realizados no Brasil, datados da década de 1980, procuram realizar um mapeamento de episódios de violência ocorridos no âmbito escolar, dando uma ênfase na questão da segurança e na questão da democracia na escola.

Mais recentemente, é realizado sob a coordenação de Codo (apud SPOSITO, 2001, um levantamento sobre a violência escolar com 52 mil professores dos sistemas públicos de ensino de todo o país. Este mapeamento revela que as agressões a alunos dentro das escolas variam de intensidade em cada estado, sendo que os maiores índices foram registrados no Distrito Federal, enquanto que o Estado do Rio de Janeiro apresentou o menor número de agressões físicas dirigidas a professores. Segundo o autor, os registros de violência que atingem alunos, professores e funcionários, é maior nas escolas públicas, em comparação com a rede privada, e nas oitavas séries do ensino fundamental e no ensino médio.

Os trabalhos que analisam as relações estabelecidas entre os próprios alunos e os estudos a respeito dos maus tratos entre os escolares, conhecidos por bullying, têm, principalmente a partir dos anos 1990, se destacado. Segundo Revilla Castro (2002), nos países escandinavos há um número menor de estudantes implicados nesse tipo de violência escolar (10\%). Na Inglaterra, na Espanha, em Portugal, Bélgica, Grécia, Canadá, Japão, China e Austrália o nível é superior (acima de 20\%) e na Alemanha e na Itália o mau trato entre os escolares é superior a $30 \%$.

O mau trato é definido pela presença de relações assimétricas entre agressores e vítimas e por ser uma relação que implica em continuidade de tempo. Para que um comportamento seja definido como mau trato é necessário que exista uma diferença de poder entre agressores e vítimas. Esta diferença de poder se produz entre pessoas em princípio consideradas iguais (REVILLA CASTRO, 2002). Segundo Revilla Castro (2002), essas agressões que ocorrem entre iguais são menos custosas e têm maiores possibilidades de passarem despercebidas e não serem castigadas.

Os estudos sobre bullying procuram examinar o sofrimento vivido por uma porcentagem de alunos causada pela conduta violenta de seus colegas em relação a ele. Estudam-se as consequências dos maus tratos tanto para os agressores quanto para as vítimas. As investigações realizadas estão dirigidas para a redução das incidências desse tipo de violência buscando melhorar a vivência escolar dos alunos submetidos aos maus tratos.

Para Olweus (1998), um aluno é agredido e se converte em vítima quando está exposto, de forma repetida e durante certo tempo, às ações negativas exercidas por outro aluno. Estas ações negativas incluem condutas como: agressões 
verbais (insultos e ameaças), agressões físicas (golpes, socos, empurrões), danos materiais, exclusão da vítima do grupo de pares, ignorar a vítima, contar mentiras e levantar falsos rumores sobre ela. $\mathrm{O}$ autor constatou, ao analisar os processos grupais, que os grupos facilitam as condutas violentas por promover uma diminuição da responsabilidade individual e uma desinibição maior dos seus membros para assumir condutas violentas.

Salmivalli (apud REVILLA CASTRO, 2002), ao estudar as relações entre pares que se formam nas salas de aula, observa que os estudantes que se comportam de forma semelhante, sejam como agressores, ajudantes dos agressores, defensores das vítimas ou observadores, na dinâmica da violência escolar, tendem a se unir entre si e formar redes de ligação. Os alunos que permanecem fora destas redes tendem a serem vítimas com maior frequência. Mynard e Joseph (apud REVILLA CASTRO, 2002) categorizaram quatro tipos principais de mau trato, que denominaram como: vitimização física, vitimização verbal, manipulação social e ataques à propriedade. As formas mais frequentes de mau trato são as agressões verbais, como insultos, ameaças e disseminação de boatos negativos sobre uma pessoa. Os insultos constituem-se na forma mais comum de agressão entre os escolares e a violência física é classificada por eles como a de menor incidência. Em geral, há uma diminuição do fenômeno, que é predominantemente masculino, em função da idade.

Os estudos evidenciam que os agressores são fisicamente mais fortes, reagem com maior agressividade, são provocadores, apresentam tendência à hiperatividade, manifestam pouca empatia com os demais e inclusive se mostram satisfeitos com o sofrimento que provocam. São egocêntricos, hedonistas e têm uma autoestima defensiva alta. Mantêm uma relação insatisfatória e hostil com a escola, pois não gostam dela e nem dos professores. No entanto, são populares especialmente dentro de seu grupo. Isto indica, segundo Revilla Castro (2002) uma possível congruência entre estas características e o descompromisso com a escola.

As vítimas em geral são mais frágeis fisicamente e às vezes têm uma aparência física desvalorizada socialmente. As vitimas são, por exemplo, os gordos, as pessoas pertencentes às minorias étnicas ou as que possuem alguma deficiência física ou mental. Em geral, aparentam insegurança e apresentam uma atitude submissa. Suas reações são pouco assertivas com tendência a reagir chorando e com o abandono da situação. Também, em geral, apresentam uma baixa autoestima, baixa autoconfiança e uma autoimagem negativa. Têm poucas relações com seus companheiros, são isoladas, pouco respeitadas e impopulares (REVILLA CASTRO, 2002). Olweus (1998), no entanto, distingue um tipo de vítima que denominou como provocativa, que se caracteriza por apresentar uma combinação de ansiedade, hiperatividade e agressividade em suas reações. 
Camacho (2001), em estudo no qual procurou investigar a relação entre os alunos, constata que as agressões entre pares são cometidas principalmente nos intervalos entre as aulas, nos pátios, no recreio e nos corredores. Na sala de aula sua incidência é menor embora esteja presente de uma forma mascarada, isto é, disfarçada como uma brincadeira. Isto sugere uma relação entre o aumento de maus tratos e agressões a uma maior possibilidade de impunidade, pela não presença de professores. Camacho (2001), concordando com os demais autores, afirma que as incivilidades que ocorrem sem parar surgem pela intolerância ao diferente, como os negros, os homossexuais, os bons alunos, os maus alunos e os feios.

A relação estabelecida entre alunos e professores é também foco de atenção dos estudos sobre a violência escolar. Dubet (2003) aponta para a tensão que se cria na sala de aula pela necessidade que os alunos têm de mostrar para os seus colegas um descompromisso com a instituição escolar e pela necessidade de serem reconhecidos por seus pares por desafiarem a autoridade. Molpeceres, Lucas e Pons (2000) e Revilla Castro (2002) corroboram essas afirmações ao assinalarem que entre os jovens da Espanha está muito presente uma atitude negativa para o trabalho educativo. Os jovens parecem fazer ostentação do seu descompromisso com a escola, pois qualquer rendimento escolar elevado é visto pelos iguais como uma conformidade com as exigências do mundo adulto. Assim, para Revilla Castro (2002) a deslegitimação da escola e dos diplomas soma-se à subcultura juvenil que privilegia o ócio frente ao trabalho formativo e desconsidera tudo que é percebido como pertencente ao mundo adulto.

Todas essas constatações têm então apontado que o cotidiano escolar é marcado pela presença de um constante desrespeito ao outro. A falta de polidez, a transgressão aos códigos de boas maneiras, se repetem sem parar, o que difere da violência das condutas criminosas ou delinquentes. Esses atos podem, parece-nos, serem enquadrados naquilo que se chama de incivilidade. Segundo Debarbieux (2001), o desrespeito na relação com o outro, provocado pelas incivilidades, é constituído de pequenas agressões cotidianas que ocorrem principalmente na escola. O desrespeito, segundo Martuccelli (2001), está associado ao fato de que os alunos na escola reivindicam um tratamento de igualdade entre professores e alunos, isto é um relacionamento não hierárquico, como se a relação com o adulto devesse seguir os mesmos moldes das relações entre pares.

Os trabalhos sobre o contexto escolar têm evidenciado a influência do clima escolar na incidência da violência na escola. Blaya (2002), em pesquisa comparativa entre França e Inglaterra, destaca a importância dos estudos sobre "clima social" na investigação da violência escolar, além dos fatores psicológicos predominantes nos estudos sobre a temática.

Alexandre e Curtis (apud REVILLA CASTRO, 2002) têm assinalado a influência do tamanho dos centros escolares e das salas de aula na produção 
da violência nas unidades escolares. Estes autores mostram que nas grandes escolas a impessoalidade do ambiente aumenta e com isso os adultos dão menor atenção aos jovens com problemas. Simultaneamente nessas grandes escolas há uma menor capacidade por parte dos adultos de controle dos comportamentos juvenis. Além disso, o tamanho das salas de aula tem como consequência a possibilidade da convivência de um maior número de alunos com problemas de comportamento, o que contribui para que o problema se agrave. Estes estudos indicam também que a exacerbação da disciplina contribui para piorar a incidência da violência escolar.

Os estudos sobre clima escolar têm também destacado que a diminuição da violência passa por uma postura firme e pelo empenho nas atividades didáticas do corpo docente, pelo compromisso dos professores com o seu trabalho e pelo tratamento não diferenciado entre os alunos de melhores e piores rendimentos escolares. Passa também pelo interesse dos alunos pela escola e pelas tarefas escolares. Quanto maior a perspectiva que o estudante vê para desenvolver-se na escola menos atos violentos ele comete.

Buratto (1998), Salles $(1998,2000)$ e Fernandes (200) afirmam que o nível de comprometimento dos alunos com as tarefas escolares varia de acordo com o professor. Segundo eles os alunos valorizam a disponibilidade que o professor tem para se comunicar com os estudantes, o quanto respeita suas ideias e o quanto permite que interfiram no processo de tomada de decisões em sala de aula. Os estudantes participam mais e melhor quando percebem que os docentes se preocupam com eles, se interessam por sua vida pessoal e pelo seu bem estar, o que é justo, mostram interesse pelos alunos e não os castigam de forma humilhante. Segundo Revilla Castro (2002), a maioria dos estudos que coletaram depoimentos de alunos a esse respeito evidencia que as agressões dirigidas aos professores estariam relacionadas ao caráter débil do professor e à sua incapacidade para manter a ordem.

Sposito (2001) aponta que as incivilidades sinalizariam um conjunto de insatisfações manifestadas pelos alunos diante de sua experiência escolar e, ao mesmo tempo, as dificuldades da unidade escolar em criar possibilidades para que tais condutas assumam a forma de um conflito capaz de ser gerido no âmbito da convivência democrática. Aponta também que essa relação entre adultos e adolescentes mediada pela escola é um reflexo maior das relações que se estabelecem entre esses jovens e a sociedade em geral.

A perda da crença na legitimidade da escola tem se constituído em outro fator desencadeador de violência no âmbito escolar. Os estudos que tratam da resistência dos alunos à escola têm apontado para a deslegitimação dos conhecimentos (CHARLOT, 2002) e diplomas que são oferecidos pela escola como desencadeadores de violência. Para Willis (1988) certas formas de violência dos 
alunos adolescentes, filhos de trabalhadores, contra a instituição escolar indicam uma resistência à escola derivada de um sentimento de que os conhecimentos escolares e o próprio diploma são insuficientes para possibilitar uma ascensão social que os coloque acima da classe operária. Também Molpeceres, Lucas e Pons (2000) têm destacado que a perda da crença na escola como fonte de conhecimentos relevantes e como instrumento de mobilidade social ascendente faz com que as autoridades escolares percam a sua legitimidade produzindo uma sensação de ausência de sentidos e de imposição arbitrária das normas e atividades escolares.

No mesmo sentido, Dubet (2003) afirma que as condutas violentas dos jovens são respostas à percepção de que é difícil atingir os objetivos preconizados pela escola como status e ascensão social. Bourdieu (1999) também aponta para a crise do sistema escolar que contraditoriamente, ao mesmo tempo em que possibilita a novas camadas da população o acesso à escola, conserva os mecanismos de exclusão social. Para Bourdieu (1999) o acesso maciço ao ensino modifica o valor simbólico e material dos diplomas desvalorizando-os. Os próprios alunos começam a perceber que o benefício é ilusório, à medida que no mercado de trabalho, o diploma não tem o valor esperado e prometido. Peralva (1997) também assinala que a massificação da escolarização faz com que a escola passe a ser destituída de sentido à medida que os diplomas por ela concedidos não garantem uma colocação no mercado de trabalho. Também para Candau (1999) a violência escolar está associada à deslegitimação da escola.

Em uma outra direção, outros estudos têm apontado para a importância do contexto familiar na produção da violência no âmbito escolar. Ao enfocarem o contexto familiar os estudos destacam uma relação entre violência infantil e/ ou juvenil e problemas nas relações familiares sejam estas entre o próprio casal ou entre os pais e seus filhos. As investigações evidenciam uma relação entre conduta violenta e ruptura da estrutura familiar (como a separação dos pais), existência de relacionamentos familiares conflitivos, pouca habilidade dos pais em lidar com as crianças e a permissividade deles.

Segundo Patterson $(1982,1992)$, os estilos parentais de imposição de disciplina marcados por práticas disciplinares autoritárias, inconsistentes e punitivas e permissivas contribuem para que as crianças sejam excluídas por seus iguais e para a ocorrência de comportamentos violentos. O comportamento agressivo que se manifesta no interior das famílias pautadas por este tipo de comportamento se generaliza. Os comportamentos violentos que até então apareciam apenas no contexto privado da família surgem também no meio escolar, tanto na sala de aula quanto na relação com os amigos, e depois nas rua. Postula-se com isso um modelo de transferência da violência: família, escola, rua. 
Os estudos que analisam as características dos familiares dos agressores têm apontado para três fatores relacionados com as normas de socialização paterna. Em primeiro lugar, uma atitude básica do principal responsável, em geral a mãe, negativa em relação ao filho, com pouca demonstração de afeto. Soma-se a isso uma permissividade para comportamentos agressivos em casa e, mesmo em alguns casos, o incentivo dos pais para que os filhos exerçam violência. E, por fim, predomina o uso de métodos disciplinares agressivos com castigos físicos e emocionais muito violentos (MELO, 1998; REVILLA CASTRO, 2002).

A localização geográfica da escola e a presença do crime organizado, isto é, o entorno escolar, e a sua possível influência na violência escolar tem também se constituído em objeto de estudo. Entretanto, esses estudos têm apontado que não há uma relação linear entre esses determinantes. Há escolas localizadas em bairros violentos que não apresentam violência e outras violentas em bairros considerados não violentos (CHARLOT, 2002; CODO, 1999, apud SPOSITO, 2001). No mesmo sentido, Sposito (2001) afirma que nem sempre os índices de violência em meio escolar coincidem com os índices mais gerais da violência que atingem os jovens de forma que a violência em meio escolar não está diretamente associada à criminalidade que atinge os jovens em algumas áreas urbanas. A autora aponta, então, para a importância de que os estudos sobre violência escolar estejam articulados com o tema da violência social, buscando compreender as conexões entre os diferentes fenômenos presentes nessa situação.

A influência da própria sociedade enquanto determinante dos comportamentos violentos na escola é problematizada, entre outros, por La Taille (1998, 2000). Para o autor os valores da sociedade penetram as relações que se estabelecem na escola. Hoje, em uma sociedade caracterizada pelo individualismo, qualquer limite, parâmetro e diretriz são vistos como práticas autoritárias que cerceiam a espontaneidade dos alunos. Para La Taille a sociedade atual favorece uma forma de socialização individualista que pode até mesmo chegar a valorizar a violência para se atingir metas pessoais e uma representação de si mesmo como violenta é passível de valorização por elas próprias.

Em geral, são essas análises que têm, direta ou indiretamente, norteado as propostas de intervenção para a prevenção da violência nas unidades escolares.

\section{Algumas propostas e programas de prevenção à violência}

As propostas para prevenção da violência nas escolas têm privilegiado diferentes aspectos. Ora essas propostas são norteadas por políticas públicas que 
apoiam a abertura das escolas aos finais de semana, ora são fundamentadas na prática das rondas escolares, ora se privilegiam ações e intervenções centradas no protagonismo juvenil, como no projeto Escola da Família. E, ora na proposição de estratégias que contribuam para a resolução de conflitos e para o incentivo ao estabelecimento de relações democráticas na escola.

Deter-nos-emos neste texto, como dito anteriormente, a refletir sobre as propostas que foram implementadas por iniciativa governamental e focalizam as relações interpessoais que permeiam o contexto escolar. Isto é, as propostas que têm como objetivo principal incentivar as relações democráticas na escola propondo estratégias para se intervir nesse sentido. Com isso, iniciativas isoladas implantadas por unidades escolares não serão objeto de análise.

No Brasil, como iniciativa governamental, parece-nos que somente no Programa Ética e Cidadania ${ }^{3}$, que incentiva as escolas a elaborar um projeto com essa temática, a questão da violência está inserida como um dos módulos a ser contemplado. O intuito do modulo não é o de criar uma escola onde os conflitos sejam eliminados mas sim o de promover ações e estratégias que mantenham os comportamentos em níveis democraticamente aceitáveis. O pré-suposto é que se não é possível postular uma ausência de conflitos em instituições que são compartilhadas por seres humanos é, no entanto, possível lidar com os conflitos de forma democrática.

O módulo que trata da violência no âmbito escolar enfatiza, nesse sentido, que as relações entre as pessoas sejam pautadas pelo diálogo e pela resolução pacífica de conflitos. Este módulo do Programa Ética e Cidadania tem como proposta promover reflexões, discussões e apontar caminhos pedagógicos para a construção de relações interpessoais democráticas no convívio escolar. Para tanto propõe a introdução das assembleias escolares, o fortalecimento dos grêmios estudantis, a implantação de estratégias de resolução e de mediação de conflitos e de estratégias de aproximação entre escola, família e comunidade.

A finalidade última deste módulo e de todo o programa é criar condições para a construção de valores democráticos que auxiliem na transformação das relações sociais, de forma a se atingir a justiça social e o aprendizado da participação cidadã nos destinos da sociedade.

Uma outra proposta fundamentada no mesmo modelo é o programa de Educación para la Tolerancia y Prevención de la Violencia en los Jóvenes, implantado na Espanha, denominado Convivir es Vivir. Este programa foi desenvolvido pelo Ministerio de Trabajo y Asuntos Sociales - Instituto de la Juventud, juntamente com os Ministerios de Educación y Cultura y Asuntos Sociales e a Universidad Complutense de Madrid e foi implantado nos Institutos 
de Educación Secundaria. Foi iniciado em 1997 e implantado em 26 centros educativos da Comunidad de Madrid (CAM).

O programa Convivir es Vivir, fundamentado no resultado de pesquisas, coordenado por Diaz-Aguado entre os anos de 1994-1997, que tinha por objetivo analisar as causas de intolerância e violência entre os jovens, tem como propósito envolver todos os membros da comunidade escolar num projeto de educação para a não violência e para a tolerância com os diferentes (DIAZ-AGUADO, 1996, 2002, 2003). O pressuposto da proposta é que a escola é tanto o espaço privilegiado para desenvolver a prevenção quanto o local onde as dinâmicas de intolerância e violência ocorrem com mais frequência. O professor é concebido como um agente facilitador do desenvolvimento de atitudes de tolerância entre os jovens e com isso contribui para a prevenção da violência e para a educação para a paz. Desta forma, o projeto tem por finalidade reduzir as variáveis de risco e potencializar as variáveis protetoras como a participação dos jovens em grupo de apoio, o aumento da autoestima e o desenvolvimento de estratégias de enfrentamento de conflitos. Diaz-Aguado assinala que os meninos agressivos têm poucas habilidades negociadoras apresentando uma maior tendência a responderem com agressividade a uma provocação.

O modelo de intervenção adotado está organizado em 7 unidades temáticas que são propostas para discussão e reflexão entre grupos de jovens nas escolas: racismo e intolerância, violência, jovens, povo cigano, imigrantes e refugiados, direitos humanos e democracia. Este material é complementado por um material de apoio para trabalhar em aula que consiste em um guia informativo para cada uma das temáticas propostas para reflexão e material complementar constituído por exercícios escritos e audiovisuais.

A proposta de intervenção para a prevenção da violência de jovens está delineada em 6 eixos estruturantes: 1- a adequação do ensino às tarefas evolutivas da adolescência. Para tanto se procura estimular o pensamento abstrato e a autonomia do adolescente. Busca-se incentivar no adolescente a noção de direitos e deveres e a importância de ser responsável. A ideia é tornar os jovens protagonistas das situações de aprendizagem; 2- a redução das condições de risco psicossocial e o desenvolvimento das competências que protegem os jovens como a adaptação ao sistema escolar, a integração em grupo de pares e o desenvolvimento da competência socioemocional; 3- a estimulação para que ocorram mudanças cognitivas, afetivas e de conduta. Procura-se desenvolver nos jovens atitudes que os levem a incorporar a tolerância e repudiar a violência na sua própria identidade e ensinar a eles a competência de resolver conflitos; 4- a discussão sobre diversas situações de intolerância para que os jovens aprendam a detectar e combater as condições que levam a isso e como superá-las; 5- o desenvolvimento nos jovens da percepção da intolerância e da 
violência como uma grave ameaça aos direitos humanos; 6- a implantação e o incentivo da democracia escolar.

A intervenção na escola se dá por meio de 4 procedimentos gerais de intervenção educativa:

1. Discussão entre pares. É proposto que os jovens participem de discussão e debates em grupos heterogêneos. Essa discussão tem por objetivo trazer para a reflexão conflitos da própria escola, notícias de jornal etc.

2. Aprendizagem cooperativa. Procura-se com esta atividade desenvolver nos jovens responsabilidades e atitudes de solidariedade em grupos heterogêneos. Propõe-se para tanto que os jovens investiguem coletivamente sobre um assunto polêmico.

3. Resolução de conflitos. Propõem-se situações que permitam aos jovens vivenciar experiências de resolver conflitos por meio de procedimentos de negociação.

4. Participação em exercícios de democracia participativa. Procura-se com esta atividade permitir ao jovem adquirir experiência de democracia participativa em grupos heterogêneos.

Uma análise avaliativa do programa mostrou que aumentou entre os jovens atitudes de tolerância, diminuição do risco de sofrer ou protagonizar violência, aceitação dos direitos humanos, disponibilidade para reflexão e discussão conjunta, resolução de conflitos por forma negociada e uma relação mais democrática entre professores e alunos e entre alunos.

\section{Considerações finais}

Assim, como vimos, essas duas propostas incorporam as discussões presentes nos estudos sobre os conflitos existentes e procuram trabalhá-los desenvolvendo estratégias que buscam incentivar um convívio escolar mais democrático, de respeito e tolerância ao outro. O eixo norteador das propostas são as técnicas que ensinam a negociação de conflitos e o incentivo a práticas democráticas na escola.

As propostas são centradas no cotidiano escolar e com uma proposta de intervenção voltada a educar os agentes escolares, alunos, professores, diretores e funcionários, a lidar com as pequenas agressões cotidianas que aparecem no desrespeito, segregação, exclusão e indiferença ao outro. Ou seja, são propostas que buscam desenvolver estratégias de intervenção para as pequenas violên- 
cias que ocorrem constantemente no âmbito escolar. E, pelo exposto, parece que essas propostas têm dado resultados positivos.

No entanto, essas propostas não destacam o papel da subcultura juvenil e adolescente no descompromisso com a escola, mesmo que tudo pareça indicar que cada vez mais os jovens aderem de forma mais precoce aos significados associados à cultura adolescente tal como são transmitidos pelos meios de comunicação.

A deslegitimação da escola como meio de ascensão social e que pode gerar um não comprometimento dos alunos com a escola e com os estudos também não é considerada. Além disso, como apontados nos estudos, não são considerados o clima escolar e o contexto familiar que consistem em outros aspectos que se somam aos demais como desencadeadores de violência.

Também a violência na escola está, muitas vezes, associada à violência institucional da própria escola, isto é, ligada à disciplina escolar, à forma como é imposta e em que grau. Assim, falar apenas da importância do estabelecimento de relações democráticas nas relações escolares pode não bastar, caso essa relação permaneça restrita a um local e a um espaço, o do programa de prevenção. E não atinja todo o contexto escolar e não promova o envolvimento da equipe gestora, dos diferentes professores e dos funcionários, ou seja, de todos os profissionais que atuam no espaço escolar.

Também é importante que se intervenha na problemática da violência de jovens na escola relacionando-a a outros tipos de violências determinadas pelas condições estruturais da sociedade. Por exemplo, a violência ligada à desigualdade social que é produzida e legitimada pelo sistema educativo.

Enfim, a violência dos estudantes não pode ser compreendida plenamente a não ser que a situemos em seu contexto social e cultural. Caso contrário, a violência escolar parece não ser mais que um problema individual, uma carência de habilidades sociais de alguns indivíduos ou quando muito causada pelo fato de o jovem pertencer a uma família desestruturada. É necessário compreender o indivíduo em sua totalidade entendendo que a sua história de vida, embora seja singular, não é um processo interior independente da sociedade. $\mathrm{O}$ social constitui o subjetivo definindo a forma pela qual o indivíduo vai se posicionando frente aos diferentes espaços sociais pelos quais transita.

Mesmo com toda a dificuldade que possa acarretar o pressuposto que deve fundamentar a elaboração de uma proposta de intervenção com a finalidade de prevenir a violência na escola é que esta é multideterminada. Não cabe, portanto, isolar um ou outro aspecto e se restringir a agir sobre eles.

As técnicas de negociação de conflitos e o incentivo às relações democráticas, embora importantes, e possam trazer resultados positivos, são insuficientes para trabalhar a violência no âmbito escolar, pois os determinantes da violência 
vão além das características individuais e grupais dos indivíduos envolvidos e não se restringem às vivências do contexto escolar. Assim, é importante que os programas de prevenção à violência ampliem a reflexão sobre as variáveis intervenientes na violência escolar, incorporando reflexões como as condições concretas de vida, os valores, preconceitos e a questão política e ideológica.

\section{REFERÊNCIAS}

BLAYA, C. Clima escolar e violência nos sistemas de Ensino Secundário da França e da Inglaterra In: DEBARBIEUX, E.; BLAYA, C. Violência nas escolas e políticas públicas. Brasília: Edições Unesco, 2002.

BOURDIEU, P. Escritos de Educação. 2. ed. Petrópolis: Vozes, 1999.

BRASIL. MINISTÉRIO DA EDUCAÇÃO. Programa Ética e Cidadania. Disponível em: < http://mecsrv04.mec.gov.br/seif/eticaecidadania/index.html>.

BURATTO, Ana Luíza Oliva. A direção do olhar do adolescente: focalizando a escola. Porto Alegre: Artes, 1998.

CAMACHO, L.M.Y. A violência nas práticas escolares de adolescentes. ANPED, GT Sociologia da Educação, 2001. 1 CD-ROM.

CANDAU, V. M.; NASCIMENTO, M. das G.; LUCINDA, M. D.A. C. Escola e violência. Rio de Janeiro: DP\&A, 1999.

CHARLOT, B. A violência na escola: como os sociólogos franceses abordam essa questão. Revista Sociologias, Porto Alegre, n.8, ano 4, p.432-443, jul./dez. 2002.

DEBARBIEUX, E. A violência na escola francesa: 30 anos de construção social do objeto.(1967-1997). Educação e Pesquisa, v. 27, n. 1, p. 163-193, jan./jun., 2001.

DIAZ-AGUADO, M. J. (Dir.). Programas de prevención de la " violencia y la exclusión social. Madrid: Instituto de la Juventud, Ministerio de Trabajo y Asuntos Sociales, 2003. 
DIAZ-AGUADO, M. J. Convivencia escolar y prevención de la violencia. Centro Nacional de Información y Comunicación Educativa, 2002. Disponível em: <http:/íwww.cnice.mecd.es/ recursos2/convivencia escolar $>$.

DIAZ-AGUADO, M. J. (Dir). Educación y desarrollo de la .tolerancia. Madrid: Ministerio de Educación y Ciência, 1996.

DUBET, F. A escola e a exclusão. Cadernos de Pesquisa, n.119, p. 29-45, 2003.

FERNANDES,D.G. Ir-remediável campo de sonhos de futuro: representações sociais da escola entre jovens estudantes de escolas públicas no sertão nordestino. 256p. Tese (Doutorado em Educação) - F.E. UFSCAR. São Carlos, 2003.

LA TAILLE, Y. Limites: três dimensões educacionais. São Paulo: Ática, 1998.

LA TAILLE, Y. Violência: falta de limites ou valor? Uma análise psicológica. In: ABRAMO, H.W.; FREITAS, M.V.; SPOSITO, M. Juventude em debate. São Paulo: Cortez, 2000. p.110-134.

MARTUCCELLI, D.; BARRERE, A. A escola entre a agonia moral e a renovação ética. Educação e Sociedade, Campinas, v. 22, n. 76, p. 258-277, 2001.

MELO, Z. M. de. Familia y violencia; supervivencia en la casa y en la calle: una vivencia en la ciudad de Recife. Tese (Doutoramento) - Universidad de Deusto, 1998.

MINAYO, M.C.S. (Org). O limite da exclusão social: meninos e meninas de rua no Brasil. São Paulo: Hucitec,1993.

MOLPECERES, M.; LUCAS, A.; PONS, D. Experiencia escolar y orientación hacia la autoridad institucional en la adolescencia. Revista de Psicología Social, v.15, n. 2, p. 87-105, 2000.

OLWEUS, D. Conductas de acoso y amenaza entre escolares. Madrid: Morata, 1998.

PATTERSON, G. R. Coercive family process. Eugene: Castalia, 1982.

PATTERSON, G. R.; REID, J.; DISHION, T. Antisocial boys. Eugene: Castalia, 1992.

PERALVA, A.T. O jovem como modelo cultural. Juventude e contemporaneidade. Revista Brasileira de Educação. ANPED. São Paulo, n. 5/6, p. 15-24, maio/ dez. 1997. 
PERALVA,A.T. Escola e violência nas periferias urbanas francesas. Contemporaneidade e Educação. São Paulo, n. 2, p. 7-25, set. 1997.

REVILLA CASTRO, J. C. La violencia de los alumnos en los centros educativos. Revista de Educación. Madrid, n.329, p.513-532, 2002.

SPOSITO, M. Juventude, pesquisa e educação. ANPED, 2001. 1 CD-ROM. (Trabalho encomendado).

SPOSITO, M. P. Estudos sobre juventude e educação. Revista Brasileira de Educação. São Paulo, n. 5/6, p. 37-52, maio/dez. 1997.

SPOSITO, M. P. Um breve balanço da pesquisa sobre violência escolar no Brasil. Revista Educação e Pesquisa, São Paulo, v. 27, n.1, p. 87-103, jan./jun. 2001.

SALLES, L. M. F.; LEITE, C. D. P.; OLIVEIRA, M. B. L. Educação, psicologia e contemporaneidade: novas formas de olhar para a escola. São Paulo, Taubaté: Cabral Universitária, 2000.

SALLES, L. M. F. Adolescência, escola e cotidiano: um discurso contrastante entre o genérico e o particular. Piracicaba, São Paulo: Ed. UNIMEP, 1998.

SILVA, J. M. A de P. Cultura escolar, autoridade, hierarquia e participação: alguns elementos para reflexão. Cadernos de Pesquisa, São Paulo, v. 112, p.125-136, 2001.

VELHO, G. Violência, reciprocidade e desigualdade. In: VELHO, G.; ALVITO, M. (Orgs.). Cidadania e violência. 2. ed. Rio de Janeiro: Editoras UFRJ/FGV, 2000. p. 11-25.

WILLIS, P. Aprendendo a ser trabalhador: escola, resistência e reprodução. Porto Alegre: Artmed, 1988.

Texto recebido em 18 de março de 2009.

Texto aceito em 21 de junho de 2009. 